Susanne Durst, Serdal Temel, Pia Ulvenblad*

\title{
Editorial: The Future of Organizations in the Age of Digital Transformation - A Critical Discussion Beyond Marketing and Buzzword
}

\section{Background to the Call}

The need for preparing for the digital transformation has been a recurrent theme in public and academic debates, and the COVID-19 pandemic has contributed considerably to actions as well.

These debates are (still) often characterized by strong imagery that praises the opportunities of digitalization in the highest possible terms. Here it sometimes seems that it does not really matter what the problem is - the answer will come from the application of advanced IT technologies; the pressure constituted by the pandemic on organizations and their individual actors have further reinforced it. Also, it is played with the fear, which is amplified by uncertainty and ignorance, of people by using, again, strong imagery that is geared to show that without a short-term realization of the digital transformation organizations (or even entire countries) will lose out. Consequences are obvious, organizations including policymakers approach the digital transformation by means of ad hoc solutions, e.g. the order of new software, thereby overlooking the crucial need of understanding the structural and cultural contexts that they are supposed to benefit from. Thus, the focus seems to be on technology adoption rather than technology adaption.

Against this background, from the research side, an urgent need has been identified to discuss the digital transformation and its possible differential implications on private and public organizations from a more balanced point of view. Thus, it has been claimed in this call that researchers should approach the digital transformation and its consequences on organizations and their future with more scrutiny and reflection. As we know from research that (technological) innovation rarely yields the consequences expected.

Therefore, scholars and practitioners were encouraged to share their reflective and critical ideas about the future of different types of organizations considering both the opportunities and challenges provided by the digital transformation.

Two papers were related to this call which applied different and methods to study their respective topics.

* Susanne Durst: Department of Business Administration, Tallinn University of Technology, Estonia

Serdal Temel: Department of Chemical Engineering, Ege University, Turkey.

Pia Ulvenblad, School of Business, Engineering and Science, Halmstad University, Sweden

mrev, 32 (2) 2021, $106-107$

BOi: 10.5771/0935-9915-2021-2-106 
The paper "Enhancing Employer Branding via High Tech Platforms: VR and Digital, What Works Better and How?" by Svetlana Bialkova and Emiel Ros, aims as outlined in the title to develop our understanding of whether and how high-tech virtual reality (VR) and digital video platforms could be used to enhance employer branding. To compare the effect of various high-tech platforms on enhancing employer branding the authors conducted a study with a leading international insurer. The findings suggest that the combination of both VR and digital video platforms can augment experiences and enhance employer brand evaluation which in turn opens up new avenues for organizations' employer branding activities and efforts.

Isabelle Aime, Fabienne Berger-Remy, and Marie-Eve Laporte's explored in their paper "The Reconfiguration of Marketing Organisation in the Age of Digital Transformation: A Paradox Perspective" how and to what extent the tensions created by digital transformation produce changes inside large marketing organizations and lead to potential reconfigurations. The study was based on a qualitative research approach involving interviews with various types of external and internal consultants either specialized in a specific digital marketing area or in charge of digital transformation. Using the theory of paradox, the authors show the complexity involved in the digital transformation of marketing. According to the findings, tensions result in three paradoxes: a learning paradox (the combination of traditional and digital marketing skills), an organizing paradox (both expertise and a holistic view), and a performing paradox (both customer and brand centricity).

We hope that these submissions are only the beginning and together with the introduction to the call will encourage and motivate researchers and practitioners alike to approach the opportunities ahead for further developing this timely and relevant topic that affects us all.

\section{References}

Dainty, A., Leiringer, R., Fernie, S., \& Harty, C. (2017) BIM and the small construction firm: a critical perspective, Building Research \& Information, 45(6), 696-709.

Kane, G. C., Palmer, D., Phillips, A. N., Kiron, D., \& Buckley, N. (2015). Strategy, not technology, drives digital transformation. MIT Sloan Management Review and Deloitte University Press, 14, 1-25.

Katz, R. L., \& Koutroumpis, P. (2013). Measuring digitization: A growth and welfare multiplier. Technovation, 33(10-11), 314-319.

Li, F. (2018). The digital transformation of business models in the creative industries: A holistic framework and emerging trends. Technovation.

Olleros, X. (2008). The lean core in digital platforms. Technovation, 28(5), 266-276.

Sebastian, I. M., Ross, J. W., Beath, C., Mocker, M., Moloney, K. G., \& Fonstad, N. O. (2017). How Big Old Companies Navigate Digital Transformation. MIS Quarterly Executive.

Singh, A., \& Hess, T. (2017). How Chief Digital Officers Promote the Digital Transformation of their Companies. MIS Quarterly Executive, 16(1). 